\title{
LAS ORACIONES DE RELATIVO CON SENTIDO CONDICIONAL EN EL LIBRO DE LOS EXENPLOS POR A.B.C.
}

\begin{abstract}
Resumen. La investigación de las destrezas discursivas en las construcciones condicionales ha hecho aflorar cuestiones que se presumían, pero también otras con las que no se contaba. Entre las primeras, se encuentra la evidencia de que no se puede generalizar. Cada forma de expresión posee unas propiedades que las hacen más propensas que otras a desempeñar determinadas funciones pragmáticas. Entre las segundas, destaca el olvido sistemático al que la lingüística española ha sometido a las oraciones de relativo con valor condicional. ¿Pueden las oraciones de relativo con indicativo asumir dicho valor?
\end{abstract}

Palabras claves: condicional, relativo, modo, exempla, pragmática.

\section{Introducción}

La deriva de los estudio del lenguaje hacia una lingüística de la comunicación ha tenido profundas repercusiones. Ha dejado atrás los principios rectores del inmanentismo. Ha favorecido que su centro de interés se haya desplazado desde la oración al texto, confiriendo especial relieve a «los factores extralingüísticos de la comunicación que inciden en la configuración verbal del discurso» (López Serena, 2003: 216). Ha renovado los objetivos de la lingüística, proponiendo nuevos temas y formas de análisis, pero también ha reactivado la revisión de aquellos que formaban parte del paradigma científico anterior.

La vuelta, en este contexto, sobre las construcciones condicionales tiene sus peajes. Implica que sus estructuras ya no son el fin en sí mismo. Representan el medio través del cual incidir en cómo funcionan y se usan en cuanto instrumento de comunicación y de interacción. Supone, pues, recuperar la dimensión social del lenguaje. Conlleva asimismo que el corpus ya no se puede concebir ni como un conjunto de textos ni como una

\footnotetext{
* Universidade de Santiago de Compostela.
} 
simple nómina de ejemplos (cf. Kabatek, 2013). Tiene entidad propia y, como tal, requiere el conocimiento previo de las condiciones pragmáticotextuales de su producción y de su recepción. Sólo así se puede tener acceso al ambiente cultural en el que se originaron, a las motivaciones que los promovieron, a los objetivos con los que se compusieron y al público al que iban dirigidos.

He optado para ello por una tradición discursiva, los exempla medievales, ni muy numerosas en sus manifestaciones, ni muy amplia en su cronología, pero con pautas comunes en su gestación, composición y propósitos. Son normalmente traducciones de carácter narrativo, destinadas a ser integradas en un discurso más amplio de tipo homelético. Buscan ilustrar y convencer, induciendo a sus destinatarios a interpretar como principios generales de conducta lo que, en un primer momento, no es más que un caso concreto y particular.

Este diseño hace del exemplo un discurso en sí mismo con una estructura textual perfectamente definida. Está planeado para que cada una de sus partes suponga un avance en el saber doctrinal que se quiere transmitir. Se inicia con una máxima latina, le sigue un dístico rimado en romance, un relato vivido u observado y se cierra con una especie de glosa, que resume el significado alegórico del cuento y sintetiza la doctrina moral gestada en las tres secciones que le preceden. Esta disposición posibilita que cada apartado responda a principios e intenciones muy distintas, presente rasgos específicos que los individualizan y recurra a las formas de expresión condicional de manera sustancialmente diferente en todas ellas. Son precisamente estas preferencias las que imponen que, por lo menos en una primera aproximación, el estudio de la condicionalidad se haga de forma individualizada, respetando cada una de las secciones propuestas.

Con ocasión de este homenaje al amigo, W. Nowikow, haré una triple selección en el objeto de análisis. Tomaré como referencia el Libro de los exenplos por A.B.C. ${ }^{1}$ Me centraré en los dísticos rimados y en un tipo muy concreto de construcción condicional. Examinaré las funciones informativas y pragmáticas que, en ese marco, desempeñan las oraciones de relativo con significado condicional y las marcas que las habilitan para asumir tal valor $y$, por último, expondré las causas por las que las relativas en indicativo se suelen obviar como signo de condicionalidad.

\footnotetext{
${ }^{1}$ Desde ahora, A.B.C. (cf. Sánchez de Vercial, 2000).
} 


\section{Relativas condicionales}

La anuencia sobre los requisitos que respaldan la lectura condicional de las relativas sin antecedente, a saber, las presididas por quien y las combinaciones el que, la que, etc. ${ }^{2}$, es alta. Si se prescinde de matices habituales también en otras construcciones ${ }^{3}$, su significado condicional se hace depender del carácter genérico o no específico del antecedente, la referencia temporal de futuro, la suspensión de la presuposición existencial y el sentido atributivo de la proposición de relativo, que determina la cualidad actancial del sujeto (Porcar, 1993: 51 y Montolío, 1999: 3711). Surge, en consecuencia, de las singularidades de su estructura y de la interpretación de la categoría modo. Nada, en principio, podría objetarse a esta caracterización salvo que, en su trasfondo, atribuye exclusivamente dicho contenido a las relativas en subjuntivo.

La unanimidad reaparece cuando se explicitan sus valores semántico-pragmáticos. Su caracterización como relativos de generalización ${ }^{4}$ ha sido clave. Generalización se suele entender como una variable que favorece la indeterminación de los agentes implicados en la acción, cuya individualidad se desvanece en beneficio de su interpretación como un colectivo, un conjunto o una clase, que sólo se concreta en el propio proceso verbal ( $c f$. Porcar, 1993: 49). Se asimila también a la transmisión de contenidos de carácter universal ( $c f$. Jesus, 2003; Garrido, 2017a, 2017b). y de eventos, hechos, habituales (Pérez Saldanya, 1999; Jesus, 2003). El problema no está, sin embargo, en la aceptación o no de dichos significados, sino en discernir a qué componente oracional se le atribuyen: ¿al relativo (Jesus, 2003; García Cornejo, 2006) o a los tiempos verbales y al modo que lo acompañan (Molho, 1975; Pérez Saldanya, 1999)?

La 'universalidad' se puede concebir como una derivación pragmática del carácter genérico del relativo, favorecida por la ausencia de antecedente, pero también por la especialización del relativo en la expresión de la tercera persona (Garrido, 2017b: 25). El rasgo 'habitual' debe, por el contrario, asignarse a las formas verbales que lo acompañan. La denotación de acciones, hechos generales, no identificables con un momento o una época concreta, sino repetidas en el tiempo, es un

${ }^{2}$ Cf. la NGLE para su distinción en relativas libres y semilibres.

${ }^{3}$ Su posición tematizada (Pérez Saldanya, 1999: 3272) y sus similitudes modo temporales con las condicionales (Keniston, 1937: 31.65).

4 Así en Gili Gaya (1961: 303) y en otros muchos. 
uso connatural al presente. El predominio del futuro de subjuntivo ${ }^{5}$ no supone objeción alguna. Alterna con el presente de indicativo desde, prácticamente, los orígenes en las condicionales, compartiendo ambos la enunciación de verdades generales, de costumbres repetidas, a partir de la cuales dictar normas y preceptos con valor universal (cf. Cano, 2014).

La nómina de relativas condicionales en A.B.C. es, de momento, una relación abierta. Se trata de un pequeño muestrario que reproducen fielmente las características reseñadas. Remiten a estados de cosas atemporales y a conocimientos generales de naturaleza moral. No están dirigidas a individuos concretos, sino, globalmente, a toda una comunidad. Buscan, en tanto actos de habla, la comprensión total por parte de sus receptores, pero también una reacción; en concreto, inducirlos a adaptar su conducta a los preceptos, a las máximas que, como dísticos rimados, resumen y anticipan el contenido del exemplo. En los dos ejemplos documentados, la renuncia al oropel y la prudencia ante los consejos:

El que quisiere bien bivir / deve de los ombres fuyr (323).

Al que mal consejo diere, / nescio es quien lo creyere (86).

Hay un segundo grupo, cuya confirmación o rechazo depende de una posibilidad no planteada. ¿Hay relativas condicionales en modo indicativo? Las pautas enumeradas hasta el momento no las contemplan. Están diseñadas para dar cuenta de las construcciones con subjuntivo. No rechazan explícitamente la presencia del indicativo. La obvian, a pesar de reconocer que, en latín (Ernout y Thomas, 2000), «la repartición de modos y tiempos es, en estas oraciones, idéntica al de las hipotéticas propiamente dichas» (Porcar, 1993: 51)6.

La postura de los estudios diacrónicos tampoco es uniforme. Los pocos que acogen las relativas condicionales o bien no reconocen las de indicativo, sí, las de subjuntivo (Pruñonosa, 1984), o bien las aceptan con unos números que sorprenden. «Por cada cinco esquemas condicionales introducidos por si, figura una estructura de relativo con valor condicional» (Garrido, 2017a: 358-359). La primacía corresponde al subjuntivo y, más concretamente, al futuro de subjuntivo (612 cláusulas de un total de 754) ${ }^{7}$. La incidencia del indicativo es algo más que testimonial. Las 86 ocurrencias registradas por Garrido (2017a: 372) constituyen más del 11\% del cómputo

${ }^{5}$ Aunque no son habituales las estadísticas sobre las formas verbales del relativo condicional (cf. Pruñonosa, 1984), las de Garrido (2017a: 372) confirman el predominio del futuro de subjuntivo (612 de un total de 754).

${ }^{6}$ Cf. la postura contraria en Rubio, para quien la marca de condicionalidad es el subjuntivo (1976, 1: 98).

${ }^{7}$ Los datos proceden de Garrido (2017a y 2017b). 
final de relativas condicionales. No es fácil entender tal porcentaje. La primera impresión invita a relacionar tal novedad con el corpus utilizado. Se intuye, aun así, que puede haber una razón más simple; en concreto, la manera de identificar las condicionales relativas. Garrido utiliza como referente el si latino o sus correspondientes partículas hebreas (2017: 184), lo que quiere decir que confiere valor condicional a todas las relativas romances que traducen una oración condicional latina con si.

Hay un testimonio en A.B.C. que recuerda este proceder:

El que en rreligion quiere entrar, / asno ha de semejar (312)

Es uno de los muchos casos dudosos que pueblan el texto. Todos muestran una estructura similar. Ocupan posición temática, las encabezan los relativos el que y quien, recurren al presente de indicativo en ambas cláusulas, corresponden en el título latino a un participio de presente y la mayoría contienen una verbo o una perífrasis de obligación en la segunda cláusula. La presencia del indicativo lo sitúa en una zona tal de indeterminación que cualquier lectura parece factible. Tiene, sin embargo, una peculiaridad. En el cuerpo de la narración, explica y desarrolla el sentido recto del título. Para ello reproduce la relativa del dístico, sustituyendo la segunda cláusula por una paráfrasis que explicita las claves para una comprensión correcta de la metáfora asno. A continuación, reformula la oración relativa, pero, bajo la forma de una condicional con si, con estas propiedades. El lugar de la metáfora lo ocupa una comparación, siempre más transparente que la primera, y sustituye el relativo generalizador por el pronombre personal de segunda persona. Sigue, pues, una técnica habitual en la literatura humanística de corte moral, que favorece el didactismo, la proximidad y la empatía con el interlocutor.

Dizen que uno, queriendo entrar en rreligion, demando a Sant Bernardo que era lo que avia menester nescessario.

E dixole: $-i$ Tu quieres ser asno?

El otro le demando: $-i$ Commo puede ser esto?

E rrespondiole: -El que quiere ser en la rreligion deve fazer todo lo que le mandaren, assy commo asno, e deve comer qualquier vianda que le dieren. E esta es la manera del asno. E si tu quieres ser rreligiosso, sufre todo trabajo commo el asno (312).

Este ejemplo puede ser crucial. Genera grandes expectativas, que, de confirmarse, inducirían a reconsiderar aspectos ya especificados y a plantearse no pocos problemas. Los de tipo teórico invitan a prescindir del rasgo "suspensión de la presuposición", válido para las relativas con subjuntivo, no, para las de indicativo. Supondría también evitar la etiqueta 
"hipotéticas" como marca general de la condicionalidad. Es un significado pragmático, susceptible, por tanto, de cancelarse contextualmente, que no afecta por igual a todas las categorías de condicionales. No se actualiza en las que, como las relativas, denotan habitualidad o atemporalidad, tampoco en las condicionales de la enunciación, las epistémicas, etc. (cf. Rodríguez Rosique, 2008: II.1.2 y Cano, 2014: 32.2.1). Impondría, igualmente, una aproximación global y detallada a las relativas, que tuviese en cuenta todas las dimensiones con alguna influencia en su interpretación condicional. Se trataría de indagar en la búsqueda de recursos formales que mostrasen el camino para una lectura condicional $\mathrm{y}$, por extensión, en las diferencias entre las relativas condicionales con indicativo y con subjuntivo. Los precedentes pasan por incidir en el modo y en sus características o ampliar el ángulo de visión a toda la construcción.

Los problemas de índole práctico aluden a las dificultades de reconocimiento del matiz condicional en las oraciones de relativo con indicativo. Las hay también cuando llevan subjuntivo, pero, en menor medida. Este produce una especie de doble relación, con el antecedente, retomándolo y especificándolos, y con el predicado de la oración principal, que invita a buscar sentidos alternativos: el causal, condicional, final, etc. El indicativo, por el contrario, lo deja casi todo al contexto. Ofrece indicios, pero tan generales (posición, correlación modo-temporal, valor genérico del relativo) que, en muy pocas ocasiones, se tiene la seguridad absoluta de que la lectura propuesta sea la única posible. Sólo en testimonios como los reseñados las dudas desaparecen. La seguridad no procede; sin embargo, de que la construcción en cuestión aporte más elementos de juicio que otras, sino de la existencia de un referente en el que sustentar su interpretación.

En realidad, salvo el modo, no hay diferencias visibles entre las condicionales en indicativo y en subjuntivo. Todas van introducidas por quien o por el que con el rasgo [+ humano], no poseen antecedente, ocupan posición inicial y tienen carácter inespecífico y generalizador. Discursivamente, su comportamiento tampoco es muy distinto. Sea cual fuere el modo, la cláusula relativa actúa como marco en el que interpretar la apódosis ${ }^{9}$, independientemente de cuál sea su nivel de actualización y de aserción. Las especificidades corresponden a la apódosis, que, en el corpus utilizado, son muy similares a las detalladas en las relativas con subjuntivo. Explicitan las circunstancias concretas que determinan la

\footnotetext{
${ }^{8}$ Rubio la llama hipersubordinación (1976, I: 98).

${ }^{9}$ Cf. Rodríguez Rosique (2008) y López Izquierdo (2015) para la historia de este concepto y su aplicación a las condicionales.
} 
recomendación, la advertencia y la orden, que se enuncian en la segunda cláusula. Las relativas con indicativo habilitan para ello dos esquemas. En ambos, el presente de indicativo es el tiempo dominante, no exclusivo ${ }^{10}$. Se alejan en el segundo miembro, al que corresponden los efectos perlocutivos buscados. Para la recomendación, se recurre, de nuevo, al presente de indicativo, bajo la modalidad de las perífrasis deónticas deber (de) y haber de, y al presente de subjuntivo, equiparables en su valor prospectivo y en su significado 'imposición mitigada, cortés'. Para la promesa, advertencia y amonestación, al futuro de indicativo. Remiten en los dos casos (indicativo subjuntivo) a un supuesto individualizado y concreto, que el relativo generalizador eleva a la categoría de norma general. Extiende su aplicación a todo el colectivo de seres humanos que comparten la cosmovisión del hombre de entonces y aceptan la relación de implicación, causal, para Cano (2014: 32.2.), entre los estados de cosas enunciados en la prótasis y en la apódosis.

El que veye a otro rrenegar / luego lo deve penar (67).

Quien por la cruz perdón demanda, / non le debe de ser denegada (99).

El que a otros quiere empesçer, / en si mesmo lo ha de padesçer (267).

El que cobdicia gloria e quiere bien venir, / venda el mundo por el que esta por venir (330).

El que faze elimosna avera habundamiento, / que por una cosa rreçibira ciento (133).

Quien non es fiel a Dios su Señor / non sera el ombre que es menor (151).

Quien a otro disfama con mentira / penara e avera a Dios en yra (239).

\section{Conclusiones}

La insistencia en las similitudes entre las relativas condicionales con indicativo y con subjuntivo no implica que no haya distinciones. Ahí está el modo para suspender la suposición existencial o para activarla ( $c f$. Molho, 1975; Porcar, 1993; Montolío, 1999), para marcar la oposición entre lo específico y lo inespecífico (Pérez Saldanya, 1999), entre lo conocido y lo eventual (NGLE), entre lo asertivo y no asertivo (Pérez Saldanya, 1999) e incluso para constituirse en marca de hipersubordinación, en una invitación a buscar contenidos de carácter oracional (Rubio, 1976). La reiteración en la ausencia de marcas específicas en las relativas en indicativo tiene muchas lecturas. Es, de entrada, una manera de entender y explicar el olvido en que han estado sumidas. Refiere también las

${ }^{10}$ Hay un ejemplo con antepresente en A.B.C. y ocho con pretérito (el que tuvo) en los romanceamientos bíblicos (Garrido, 2017a: 372). 
dificultades que comporta la identificación de su significado condicional, no muy diferentes, por otro lado, de las que muestran otras estructuras con el mismo valor, como los gerundios o participios. Supone asimismo un aliciente para su investigación, que debería ir más allá de su propia forma de expresión y replantearse el concepto de condición y, por extensión, su tipología (cf. Montolío (1999), Rodríguez Rosique (2008) y Cano (2014). Conlleva, por último, el reconocimiento de que, en el estado actual de investigación, su interpretación condicional depende en exceso del entorno discursivo. Tiene un fuerte componente subjetivo que no ayuda a decisiones definitivas y concluyentes.

\section{Bibliografía}

CANO, R. (2014). «Oraciones condicionales», en C. COMPANY (dir.), Sintaxis histórica de la lengua española. Tercera parte: Preposiciones, adverbios y conjunciones. Relaciones interoracionales, 3. México: Fondo de Cultura Económica, 3905-4092.

ERNOUT, A. y THOMAS, F. (2000). Syntaxe Latine. Paris: Klincksieck.

286 GARCÍA CORNEJO, R. (2006). Morfología y sintaxis de que en la Edad Media. Sevilla: Universidad de Sevilla.

GARRIDO SEPÚLVEDA, CL. (2017a). La expresión de la condicionalidad en los romanceamientos bíblicos medievales. Tesis doctoral. Barcelona: Universidad Autónoma de Barcelona.

GARRIDO SEPÚLVEDA, CL. (2017b). «Mecanismos sintácticos de significación condicional en las biblias romanceadas bajomedievales», Res Diachronicae, $14 / 2,13-29$.

GILI GAYA, S. (1961). Curso superior de sintaxis española. Barcelona: Vox.

JESUS DE, I. T. (2003). «Construções condicionais proverbiais: uma visão sociocognitiva», Alfa, 49/1, 139-160.

KABATEK, J. (2013). «¿Es posible una lingüística histórica basada en un corpus representativo?», Iberorromania, 77, 8-28.

KENISTON, H. (1937). The Syntax of Castilian Prose. The Sixteenth Century. Chicago: University of Chicago Press.

LÓPEZ IZQUIERDO, M. (2015). «Orden de cláusulas y función informativa en las oraciones condicionales del español del siglo XV», en M. LÓPEZ IZQUIERDO y M. CASTILLO LLUCH (coord.), El orden de palabras en la historia del español y otras lenguas iberorromances. Madrid: Visor Libros.

LÓPEZ SERENA, A. (2003). «Algunos aspectos epistemológicos de la lingüística contemporánea», Res Diachronicae, 2, 212-220.

MOLHO, M. (1975). Sistemática del verbo español. (Aspectos, modos y tiempos), I y II. Madrid: Gredos. 
MONTOLÍO, E. (1999). «Las construcciones condicionales», en I. BOSQUE y V. DEMONTE (dirs.), Gramática descriptiva de la lengua española. Madrid: Espasa, 3643-3737.

PÉREZ SALDANYA, M. (1999). «El modo en las subordinadas relativas y adverbiales», en I. BOSQUE y V. DEMONTE (dirs.), Gramática descriptiva de la lengua española. Madrid: Espasa, 3253-3322.

PORCAR, M. (1993). La oración condicional: La evolución de los esquemas verbales condicionales desde el latín al español actual. Valencia: Universitat Jaume 1.

PRUÑONOSA, M. (1984). «Algunas consideraciones sobre las proposiciones de relativo en textos medievales», en Estudis en memoria del professor Manuel Sanchis Guarner, 2. Valencia: Universidad de Valencia, 249-256.

NGLE - Real Academia Española (2009). Nueva gramática de la lengua española. Madrid: Espasa Libros.

RODRÍGUEZ ROSIQUE, S. (2008). Pragmática y gramática: condicionales concesivas en español. Frankfurt: Peter Lang.

RUBIO, L. (1976). Introducción a la sintaxis estructural del latín. Barcelona: Ariel.

SÁNCHEZ DE VERCIAL, CL. (2000). Libro de los exenplos por a.b.c. Edición crítica de J. E. KELLER y S. SCARBOROUGH. Madrid: Ediciones Académicas. 